NBER WORKING PAPER SERIES

ALTERNATIVE TESTS OF RATIONAL EXPECTATIONS
MODELS: THE CASE OF THE TERM STRUCTURE

Robert J. Shiller

Working Paper No. $\underline{563}$

NATIONAL BUREAU OF ECONOMIC RESEARCH

1050 Massachusetts Avenue

Cambridge MA 02138

October 1980

This paper was presented at the Conference on Model Selection, Gainsville, Florida, April 18-19, 1980. Research was supported by NSF Grant \#SOC - 7907561. Roger Huang provided research assistance. Discussions with Roberto Mariano and Angelo Melino were helpful. The research reported here is part of the NBER's research program in Financial Markets and Monetary Economics. The views expressed here are my own and should not be attributed to the National Science Foundation or the National Bureau of Economic Research. 


\title{
Alternative Tests of Rational Expectations Models: The Case of the Term Structure
}

\begin{abstract}
A linearized version of the rational expectations models of the term structure is put forth in terms of a complete vector of equally spaced observations along the yield curve. A data series on intermediate maturity yields which meets the specifications of the model is presented. The model is tested against a specific and easily interpreted alternative. Earlier studies of rational expectations models, which used "volatility tests" or "likelihood ratio tests," are discussed.
\end{abstract}

Robert J. Shiller

National Bureau of Economic Research 1050 Massachusetts Avenue Cambridge, Massachusetts 02138

(617) $868-3964$ 
Alternative Tests of Rational Expectations Models:

The Case of the Term Structure

Robert J. Shiller*

\section{Introduction}

The aims of this paper are:

1. To display a linearized version of rational expectations models of the term structure of interest rates in terms of a complete vector of equally spaced observations along the yield curve. The linearized version is essentially the same as that which I derived (Shiller [1979]) for two observations along the yield curve: the one-period rate and the perpetuity rate. The more general vector representation enables a more complete specification of hypotheses.

2. To present a data set on U.S. government bond yields which accurately fits the description of the data assumed in the model.

3. To present an alternative hypothesis in terms of the vector of observations along the yield curve that represents an easily interpreted alternative to the model, and to present a posterior odds ratio between the hypotheses.

4. To comment on a recent study by Sargent [1979] which appears to confirm the expectations model, in contrast to my conclusion (Shiller [1979|) that longterm interest rates appear to be too "volatile" to accord with the model. The data and sample period used here are closer to that of Sargent and represents some improvement over Sargent's. It will be shown that Sargent's procedure did not test all of the restrictions imposed by the model. Not only did he first difference the data, but also he omitted restrictions on the stochastic properties of the differenced daca. hie threw away the very restrictions used to establish the volatility restrictions which I used.

*Associate Professor of Economics, University of Pennsylvania and Research Associate, National Bureau of Economic Research. 


\section{Data Set}

The data set used here (Table III below) consists of nine semi-annual series of yields on $1 \frac{1}{2} \%$ five year Treasury notes (series designation EA and EO), each series representing yields of bonds with a given time to maturity, from 6 months in multiples of 6 months up to 4.5 years. Yields are computed from midpoints of bid-asked price spreads for the end of March and September as provided on the Rodney White Center Government Bonds Tape maintained by the wharton School. $1 /$ This data is ideal in that bonds were issued each April 1 and October 1 from 1951 to 1978, on the same day that the $1 \frac{1}{2} \%$ coupons were paid on outstanding notes. The notes are not callable, may not be redeemed at par in payment of estate taxes, and the appreciation in price from original issue discount was, throughout the sample period, taxed as income.

The sample was confined to the interval 1955-II to 1973-I because over this interval there were always fairly large quantities (ranging from 33 million dollars to over a billion dollars) of bonds in each of the nine maturity categories outstanding. We might wish for a series based on uniformly large quantities, but no such series which shares the other advantages of this series appears to be available in the United States. Data on bonds with the full maturity of five years were not used, because of possible anomalies in the pricing of new issue bonds (Shiller and Modigliani [1979]).

The data series represent a clear improvement over the series used by

$1 /$ The tape prepared by John Bildersee and described in Bildersee [1975] has as its primary source Salomon Brothers quote sheets. The prices are usually identical to the corresponding figures quoted in the first issue in April and october of the Connercial and Financial Chronicle, differing sometimes by a few 32nds of a point. After 1969, when quantities in some maturities fell below $\$ 100 \mathrm{nilliom}$, the discrepancies between the two sources are bigger and more conmon, reflecting perhaps the relative thinness of the market when smaller quantities of the bonds were outstanding. 
Sargent which he took from Salomon Brothers' book, An Analytical Record of Yields and Yield Spreads. The Salomon Brothers data are "yield curve" data based upon judgmental interpolation of yields on heterogeneous bonds. Sargent used quarterly data on five year and three month rates from 1953-II to 1971-IV.

\section{The Simple Expectations Model of the Term Structure}

The simple expectations models of the term structure as we shall define

it can be hititen:

$$
R_{t}^{(i)}=\frac{1-\gamma}{1-\gamma} \sum_{K=0}^{i-1} \gamma E_{t} R_{t+K}^{(1)}+\phi_{i}=E_{t}\left(R_{t}^{* i}\right)+\Phi_{i}
$$

where $R_{t}^{(i)}$ is the yield to maturity at tine $t$ of a bond maturing at tine $t+i$, $R_{t}(1)$ is the nne-period rate, and $\Phi_{i}$ is the constant liquidity premium. $2 /$ $R_{t}^{* i}:(1-\gamma) /\left(1-\gamma^{i}\right){ }_{k}^{i-1} \sum_{n}^{k} R_{t+k}^{(1)}$ is the "ex-post rational i period rate". In the empirical work data will be demeaned so that $\Phi_{i}$ will drop out. We thus disregard it in what follows. $E_{t} R_{t+K}^{(1)}$ is the mathematical expectation of $R_{t+K}^{(1)}$ conditional on all information available at time $t$. The information includes all current and past interest rates at time $t$ and perhaps other information. The weighting scheme in (1) is truncated exponential scaled so that the sum of the coefficients is one. It was shown in Shiller $|1979|$ that (1) is a useful approximation, based on a linearization argument, to a number of variants of the expectations model of the term structure, where $r=1 /(1+c)$ and $c$ is the coipon rate per period on the bond. In the limiting case of a discount bond, as (: approaches zero, (1) reduces to a simple average of expected one-period rates. In practice, however, a]l but the shortest bonds carry coupons. The one-period holding return on an i-period bond is $\mathrm{H}_{t}^{(i)}=$

$2 /$ Throughout the paper, superfluous parentheses are used to distinguish superscripts from exponents. 
$\left(P_{t+1}^{(i-1)}-P_{t}^{(i)}+C\right) / P_{t}^{(i)}$ where $P_{t}^{(i)}$ is the price of the i-period bond so that $P_{t+1}^{(i-1)}-P_{t}^{(i)}$ is the capital gain and $C$ is its coupon. In our data, price, coupon and other yields are expressed as fractions of one, rather than in percent as is customary. One must multiply C or H by 200 to arrive at the annual percent, and $\mathrm{P}$ by 100 to arrive at price as quoted. The holding period yield can also be written in terms of the yields $R_{t+1}^{(i-1)}$ and $R_{t}^{(i)}$, since price is a function of yield. As described in Shiller [1979], if this expression is then linearized around $R_{t+1}^{(i-1)}=R_{t}^{(i)}=C$, one finds a linearized approximation to ${ }_{t}^{(i)}: \tilde{H}_{t}^{(i)}=\left(R_{t}^{(i)}-\gamma_{i} R_{t+1}^{(i-1)}\right) /\left(1-\gamma_{i}\right)$ where $\gamma_{i}=\left(\gamma-\gamma^{i}\right) /\left(1-\gamma^{i}\right)$. Expression (1) is then the solution to the rational expectations model found by setting $E_{t} H^{(i)}=R_{t}^{(1)}$ for all $i$ and $t$, which implies that $R_{t}^{(i)}=\gamma_{i} E_{t} R_{t+1}^{(i-1)}$ $+\left(1-\gamma_{i}\right) R_{t}^{(1)}$. To derive (1), one proceeds by recursive substitution, first replacing $R_{t+1}^{(i-1)}$ in this expression yielding an expression in $E_{t} R_{t+2}^{(i-2)}$ and $R_{t}^{(1)}$. Then one replaces $R_{t+2}^{(i-2)}$ and so on, until one arrives at (1). No terminal condition assumptions need be made in arriving at this solution.

The $i-1$ period forward rate applying to next period, $F_{t+1, t}^{(i-1)}$, is the yield the $i$-period bond would have to have in period $t+1$ in order for $H^{(i)}$ to equal $R_{t}^{(1)}$. $F_{t+1, t}^{(i-1)}$ can be expressed in terms of $R_{t}^{(i)}$ and $R_{t}^{(1)}$ and if this (implicit) expression is linearized around $R_{t+1}^{(i-1)}=R_{t}^{(i)}=C$ we find the linearized approximation to $F_{t+1, t}^{(i-1)}: \tilde{F}_{t+1, t}^{(i-1)}=\left(R_{t}^{(i)}-\left(1-\gamma_{i}\right) R_{t}^{(1)}\right) / \gamma_{i}$. The model (1) can also be described as the solution to the rational expectations model obtained by setting the linearized forward rate equal to the expected spot rate: $\ddot{F}_{t+1, t}^{(i-1)}=E_{t}\left(R_{t+l}^{(i-1)}\right)$ for all $i$ and $t$, by the same recursive substitution.

The linearization which enables us to use 11 and $\vec{F}$ in place of $H$ and $F$ is quite accurate. The correlation between $\tilde{H}_{t}^{(i)}$ and $H_{t}^{(i)}$ over our sample period ranges from .999767 for $i=9$ to .999992 for $i=2$. The correlation between 
$F_{t+1, t}^{(i)}$ and $F_{t+1, t}^{(i)}$ exceeds .99999 for all $i$. Thus the distinction that is often made between models equating expected one-perfod holding yields and models setting forward rates equal to expected spot rates is not important in practice. $3 /$

We will define a column vector of interest rates with maturities ranging from 1 to $n, R_{t}=\left|R_{t}^{(1)}, R_{t}^{(2)}, \ldots R_{t}^{(n)}\right|$. In our data, $n=9$. The autocovariance function for the vector $\tilde{R}_{t}$ is $B(K)=E\left(R_{t} R_{t-K}^{\prime}\right)$ where $R_{t}$ has been demeaned. By writing $B$ as a function of $K$ but not $t$ we are assuming stationarity. $B(K)$ is an nxn matrix which is a function of the scalar $K$, and $B(0)$ is the variance matrix for the vector $R_{t}$. From the definition of $\tilde{H}_{t}(i)$ we can define the vector $\tilde{H}_{t}=\left|\tilde{H}_{t}^{(1)} \tilde{H}_{t}^{(2)}, \ldots \tilde{H}_{t}^{(n)}\right|$, as $\tilde{H}_{t}=U R_{t}-V R_{t+1}$ where $\mathrm{U}$ and $\mathrm{V}$ are nxn natrices. Our model then says $\operatorname{cov}\left(\left(\tilde{H}_{t}-L_{t}^{(1)}\right), R_{t-j}\right)=0$ where $L$ is an nx 1 vector whose elements are all ones and $\mathfrak{j}>0$. The restrictions the model imposes on the stochastic properties of the $R_{t}$ vector can then be written as:

$$
N B B_{i .}+N i_{i+1}=0 \quad j \geq 0
$$

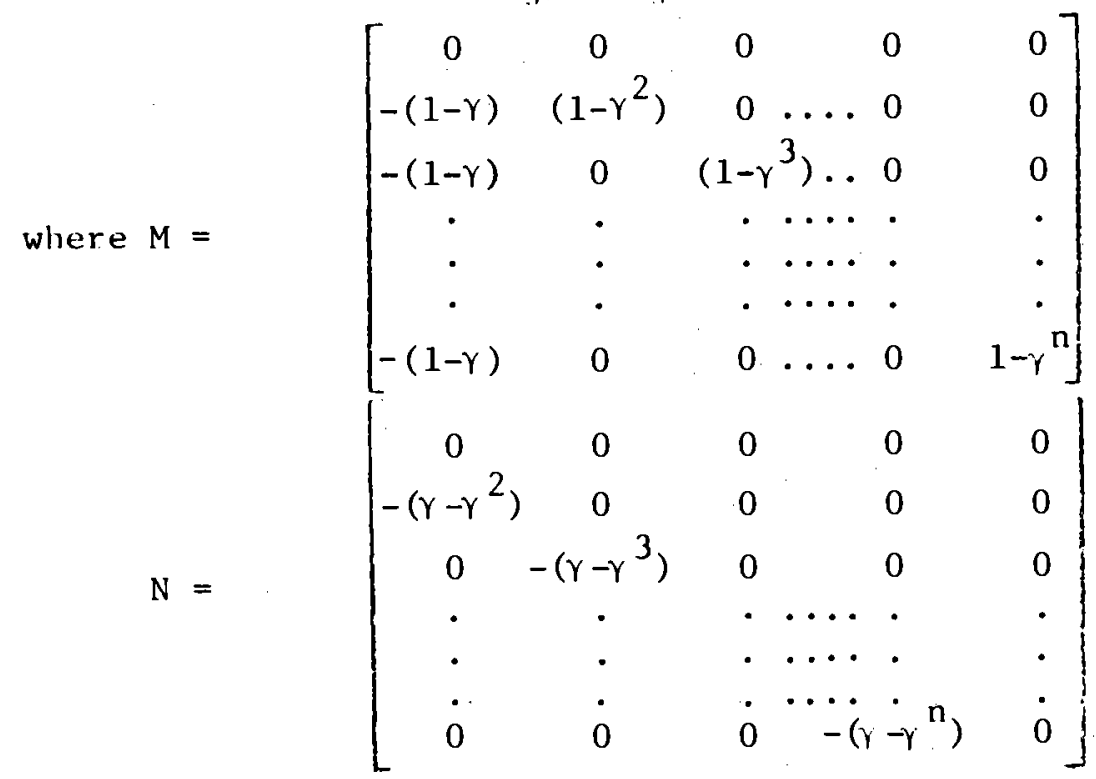

3/ We note that $\mathrm{F}_{t+i, t}^{(1)}$, the one-period forward rate applying to a time $i$ periods in the future, shows a correlation exceeding .99999 for all i with $F_{t+i}(1)$, the linearized one-period forward rate defined by $\tilde{F}_{t+i, t}^{(1)} \equiv\left(\left(1-\gamma^{i+1}\right) R_{t}^{(i+1)}-\right.$ $\left.\left(1-\gamma^{i}\right) R_{t}^{(i)}\right) /\left(\gamma^{i}-\gamma^{i+1}\right)$. The linearized $i$-period forward rate is related to the linearized 1-period forward rates by $\tilde{F}_{t+1, t}^{(i)}=\frac{(1-\gamma)}{\left(1-\gamma^{i}\right)} K_{=0}^{i-1} K_{\tilde{F}}(1)$ 
These are straightforward linear restrictions on the autocovariance function of $R_{t}$. If the generalized likelihood ratio principle is used to devise a test of these restrictions given data on the vector $R_{t}$, then with certain normality and homoscedasticity assumptions the test will amount to a series of ordinary least squares regressions of $\mathrm{H}_{\mathrm{t}}^{(i)}-\mathrm{R}_{\mathrm{t}}^{(1)}$ onto current and lagged $R_{t} i=2, \ldots n$ and $F$-tests on their coefficients or their multivariate analogues. The reason for such regressions is intuitive. $\tilde{H}_{t}^{(i)}-R_{t}^{(1)}$ is by our model an "inovation" which cannot be forecasted based on information at time $t$. Since $\ddot{H}_{t-1}^{(i)}-$ $R_{t-1}^{(1)}$ is known at time $t$, the residuals are serially uncorrelated.

In Shiller [1979b] it was shown that the restrictions on the autocovariance function between the perpetuity yield $R_{t}^{(\infty)}$ and $R_{t}^{(1)}$ imply bounds on the variance of $\tilde{H}_{t}^{(\infty)}-R_{t}^{(1)}$ for given variance of $R_{t}^{(1)}$. The inequality restrictions suggested a test of market efficiency which is recommended by its simplicity and intuitive plausibility. The bound appears to be exceeded, i.e., long-term interest rates appear to be too "volatile" to accord with the model. To derive from (2) an analogous bound on the variance of $\tilde{H}_{t}^{(i)}-R_{t}^{(1)}$ for given variance of $R^{(1)}$ and for sinall $i$, we use the fact that $\tilde{H}_{t}^{(i)}-R_{t}^{(1)}=\sum_{j=1}^{t_{i}} \gamma^{i}\left(E_{t}\left(R_{t+j}^{(1)}\right)-E_{t+1}\left(R_{t+j}^{(1)}\right)\right)$. By arguments parallel to those presented in Shiller [1979a], it is easily established that $\operatorname{var}\left(\mathrm{II}_{t}^{(i)}-\mathrm{R}_{t_{i-1}}^{(1)}\right.$ ) is maximized if $\mathrm{R}_{t}^{(1)}$ is an (i-1) order moving point average process $R_{t}^{(1)}=\sum_{j=1}^{i-1} \gamma^{i} \varepsilon_{t+i}$ where $\varepsilon_{t}$ is white noise. As was established in that paper, if $\operatorname{var}\left(\tilde{H}_{t}^{(i)}-r_{t}\right)$ is to be maximized, the elements in the sumnation which comprise it must be perfectly positively correlated. Moreover, if we assume stationarity then $\operatorname{var}\left(R_{t}^{(1)}\right)=\sum_{j=l}^{\infty} \operatorname{var}\left(E_{t}\left(R_{t+j}^{(1)}\right)-E_{t+1}\left(R_{t+j}^{(1)}\right)\right)$

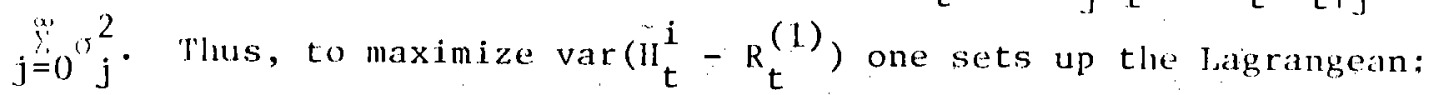

$$
L=\left(\sum_{j=0}^{i-2} \gamma^{j+1} \sigma_{j}\right)^{2}+\lambda\left(\operatorname{var}\left(R_{t}^{(1)}\right)-\sum_{j=0 j}^{\infty} \sigma 2\right)
$$

Differentiating with respect to $\sigma_{j}, j=0 \ldots \infty$ and setting to zero one establishes 
the form of the moving average process. Evaluating the summations one finds the upper bound to $\operatorname{var}\left(\tilde{H}_{t}^{(i)}-R_{t}^{(1)}\right)$. It follows that:

$$
\sigma\left(\tilde{H}_{t}^{(i)}\right) \leq a_{i} \sigma\left(R_{t}^{(1)}\right)
$$

where $a_{i}=\left(\left(1-\gamma^{2 i}\right) /\left(1-\gamma^{2}\right)\right)^{\frac{1}{2}}$ and $\sigma$ denotes standard deviation. This inequality reduces to inequality $I-1$ in Shiller [1979b] as $i$ approaches infinity while for low $i, a_{i} \equiv \sqrt{i}$. This inequality is violated by sample standard deviations for $i \geq 4$ but is not violated by $i \leq 3$ (Table I).* The violations of the inequality are most strong for the highest $i$ in our data but still less dramatic than the violation observed with really long-term interest rate data as reported in Shiller $[1979]$. The violation of the inequality for 4.5 year bonds is less dramatic than that reported by Singleton $[1980]$ for 5 year bonds. He also used a six-month short rate and a similar sample but with monthly data: 1959-I to 1971-VI. Perhaps his more dramatic results stem from his decision to subtract linear trends from the data, and in effect assume the trends were known by the market in advance. Any such assumption has the effect of reducing the uncertainty about future interest rates and thus reducing the permissible volatility of long rates according to the expectations model. Ultimately the inequality tests must hinge on our priors as to the reasonableness of such assumptions. Although these results suggest that the interest rates $R_{t}^{(i)}$, i $\geq 4$ are too volatile to accord with the model, we shall not attempt here (as did Lekoy and Porter $[1980]$ and Singleton $[1980])$ to derive a formal test of the model based on variance statistics but will develop regression tests below.

In his paper [1979] Sargent emphasized that the model placed complicated nonlinear restrictions on the autocovariance function of the vector $Z_{t} \equiv\left|R_{t}^{(1)}, R_{t}^{(n)}\right|$; *'The standard deviations of the data from the source used by Sargent, Salomon Brothers' $\Lambda$ n Analytical Record are very close to those reported here. For example, the standard deviation over our sample, using the March + September Solomon Brothers data, of: $\mathrm{R}^{(2)}$ was .0071 , of $\mathrm{R}^{(8)}$ was .0066 . 
TABLE I

Standard Deviations of Interest Rates and Holding Period Yields

\begin{tabular}{|c|c|c|c|c|c|c|}
\hline (1) & (2) & (3) & (4) & (5) & (6) & (7) \\
\hline i & $\sigma\left(R^{(i)}\right)$ & $\sigma\left(H^{(i)}\right)$ & $\sigma\left(\tilde{H}^{(i)}\right)$ & $a_{i}$ & $a_{i} \sigma\left(R{ }^{(1)}\right)$ & $\sigma\left(\tilde{H}^{(i)}\right) / a_{i} \sigma\left(R{ }^{(1)}\right)$ \\
\hline 1. & .0081 & .0081 & .0081 & 1.00 & .0081 & $\ldots$ \\
\hline 2 & .0077 & .0098 & .0097 & 1.409 & .0114 & .853 \\
\hline 3 & .0071 & .0135 & .0134 & 1.719 & .0139 & .964 \\
\hline 4 & .0070 & $\begin{array}{l}.0178 \\
(.0149)\end{array}$ & $\begin{array}{l}.0176 \\
(.0148)\end{array}$ & 1.978 & .0161 & 1.09 \\
\hline 5 & .0068 & $\begin{array}{l}.0206 \\
(.0172)\end{array}$ & $\begin{array}{l}.0204 \\
(.0171)\end{array}$ & 2.203 & .0179 & 1.14 \\
\hline 6 & .0066 & $\begin{array}{l}.0243 \\
(.0203)\end{array}$ & $\begin{array}{l}.0240 \\
(.0202)\end{array}$ & 2.405 & .0195 & 1.23 \\
\hline 7 & .0065 & $\begin{array}{l}.0282 \\
(.0237)\end{array}$ & $\begin{array}{l}.0279 \\
(.0234)\end{array}$ & 2.588 & .0210 & 1.08 \\
\hline 8 & .0064 & $\begin{array}{l}.0311 \\
(.0261)\end{array}$ & $\begin{array}{l}.0307 \\
(.0258)\end{array}$ & 2.756 & .0223 & 1.38 \\
\hline 9 & .0063 & $\begin{array}{l}.0336 \\
(.0282)\end{array}$ & $\begin{array}{l}.0332 \\
(.0278)\end{array}$ & 2.912 & .0237 & 1.40 \\
\hline
\end{tabular}

The $R^{(i)}$ series (yield to maturity of a bond maturing in $i$ periods) appear in Table IIl. $H^{(i)}$ (the one-period holding yield), $\sim_{H}^{(i)}$ (the linearized one-period holding yield) are defined from data in Table ILI as described in the text, and $a_{i}$ is defined in expression 4. The expectations model implies that the number in column 4 ought to be less than the corresponding number in column 6 , or that the number in column 7 ought to be less than one. Numbers in parentheses are lower bounds of one-sided $95 \%$ confidence interval based on the assumption independent normal observations. Sample period is 1955-II to 1972-II. 
analogous to those previously noted in Sutch [1968] and Shiller [1972]. The reason for such complicated restrictions is that the data vectors contained only two interest rates: a long rate and the one-period rate. By omitting the intervening rates $R_{t}^{(2)}, R_{t}^{(3)} \ldots R_{t}^{(n-1)}$ from the data vector, straightforward linear restrictions on the autocovariance function were converted into nonlinear restrictions. One finds these nonlinear restrictions by a series of recursive substitutions to eliminate the covariances relating to the variables $R_{t}^{(2)}, R_{t}^{(3)}, \ldots R_{t}^{(n-1)}$, from the set of restrictions (2), substitutions which yield nonlinear relationships. To see why this is the case in another way, consider the simple relationship between the regression coefficient $\beta$ of $\tilde{R}_{t}^{(n)}$ on $\tilde{R}_{t}^{(1)}$ and the autoregressive coefficient $\rho$ of $\tilde{R}_{t}^{(1)}$ on $\tilde{R}_{t-1}^{(1)}$. The model (1) implies that a theoretical regression of $R_{t}^{(i)}$ onto $R_{t}^{(1)}$ is the same as a regression of $\left((1-\gamma) /\left(1-\gamma^{i}\right)\right) \underset{j=0}{i} \sum_{0}^{1} \gamma_{R}^{j} R_{t+j}^{(1)}$ onto $R_{t}^{(1)}$. By the law of iterated projections, a regression of $R_{t+j}^{(1)}$ onto $R_{t}^{(1)}$ is $\rho^{j-1}$. Hence, $B=\left((1-\gamma) /\left(1-\gamma^{i}\right)\right)$. $\left.\sum_{j=0}^{i-1} \gamma^{j} \rho^{j-1}=\left((1-\gamma)\left(1-(\gamma \rho)^{j}\right)\right) /\left(1-\gamma^{i}\right) /(1-\gamma \rho)\right)$. Clearly, if $i>2$ this is a nonlinear relationship between $B$ and $F$.

Sargent [1979] further specified the model by assuming that the first difference of the bivariate process $z_{t}$ was fourth order autoregressive and that the innovation is bivariate normal with a general variance matrix:

$$
\Delta Z_{t}=\sum_{i=1}^{m} \alpha_{i} \Delta Z_{t-i}+E_{t}
$$

where $\alpha_{i}, i=1, \ldots \mathrm{n}$ are $2 \times 2$ matrices of coefficients, and $\varepsilon_{t}$ is the 2 element innovation vector $E\left(\varepsilon_{t}\right)=0, E\left(\varepsilon_{t} \varepsilon_{t}^{\prime}\right)=V, E\left(\varepsilon_{t} \varepsilon_{t-k}^{\prime}\right)=0, k \neq 0$. He wrote the likelihood conditional for $\mathrm{T}+\mathrm{m}$ observations of $\mathrm{Z}_{t}$ in the form: 


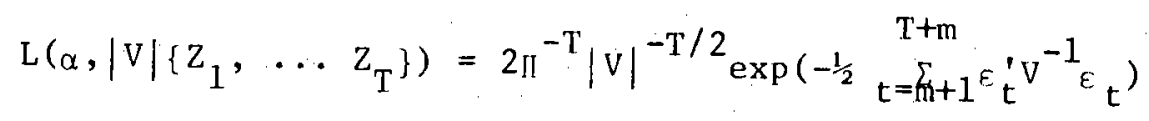

where $\varepsilon_{t}=\Delta Z_{t}-{ }_{i} \underline{\Sigma}_{1} \alpha_{i} \Delta Z{ }_{t-i}$. This form of the likelihood function is conditional on the first $m$ observations $\Delta z_{1}, \Delta z_{2}, \cdots \Delta z_{m}$, which are treated as if they were not generated by this model. This form might be justified on the basis of analytical convenience. By representing the model in first difference form, Sargent effectively assumed that the variance of $\mathrm{R}_{\mathrm{t}}^{(1)}$ is infinite, and hence the inequality (4) is assumed satisfied.

Sargent did not test all of the restrictions imposed by the model even if we assume that ${ }_{t}$ is unstationary and must be differenced to impose stationarity. The restrictions on the $\alpha_{i}, i=1, \ldots m$, which Sargent tested are those imposed by the requirement that [ $\left((1-\gamma) /\left(1-\gamma^{n}\right)\right)\left({ }_{k=0}^{n} \gamma^{-1}{ }^{k} \Delta R_{t+k}^{(1)}-\Delta R_{t}^{(n)]}\right.$ (where for Sargent $\gamma=1$ ) be uncorrelated with all lagged variables $\Delta R_{t-1}^{(1)}, \Delta R_{t-2}^{(1)}$, $\ldots \Delta \mathrm{R}_{\mathrm{t}-\mathrm{m}}^{(1)}$, and $\Delta \mathrm{R}_{\mathrm{t}-\mathrm{L}}^{(\mathrm{n})}, \Delta \mathrm{R}_{\mathrm{t}-2}^{(\mathrm{n})}, \ldots \Delta \mathrm{R}_{\mathrm{t}-\mathrm{m}}^{(\mathrm{n})}$. The implications Sargent did not test can be seen first by noting the forecast error of the levels $\left.\xi_{t} \equiv \mid(1-\gamma) /\left(1-\gamma^{n}\right)\right)$ $\sum_{k=0}^{n-1} \gamma^{k} R_{t+k}^{(1)}-R_{t}^{(n)}|=|\left((1-\gamma) /\left(1-\gamma^{n}\right)\right) \sum_{k=1}^{n-1} \gamma_{j=1}^{k} \sum_{t}^{k} \Delta R_{t+j}^{(1)}-\left(R_{t}^{(n)}-R_{t}^{(1)}\right) \mid$ and the spread $R_{t}^{(n)}-R_{t}^{(1)}$ are stationary under his assumptions.

Since the projection of the forecast error on information dated $t-1$ or earlier is zero, it follows that $\xi_{t}={ }_{k=0}^{n-1} B(k) \varepsilon_{t+k}-\left(\varepsilon_{2}-\varepsilon_{1}\right)$ where $B(k) k=0, \cdots n-1$ are $2 \times 1$ vectors of coefficients of $E$ for $\left((1-\gamma) /\left(1-\gamma^{n}\right)\right)$ $\sum_{k=1}^{n-1} \gamma^{k} j_{j}^{k} \Delta R_{t+j}^{(1)}$ minus its optimal forecast linear in $\Delta R_{t-1}^{(1)}, \Delta R_{t-2}^{(1)}, \ldots \Delta R_{t-m}^{(1)}$, $\Delta R_{t-1}^{(n)}, \Delta R_{t-2}^{(n)}, \cdots \Delta R_{t-m}^{(n)}$. The coefficients $B(k)$ are found by recursive substitution in terms of the coefficients of the autoregressive representation. Since $\varepsilon_{t}$ is known at time $t$, if $\xi_{t}$ is to be unforecastable at time $t$, the term $\varepsilon_{t}$ must drop out of the expression for $\xi_{t}$, which means that cither $B(0)=[1,-1]^{\prime}$ or there is a linear dependence between $\varepsilon_{2 t}$ and $\varepsilon_{1 t}$. The former imposes additional restrictions on the coeffieicents of the autoregression, the latter implies that $V_{t}$ is singular. 
This point was also established in a different way by Melino [1981]. The restriction that $\xi_{t}$ is uncorrelated with contemporaneous level variables is the basis for the volatility tests reported in Shiller [1979] and is the basis for the regression tests below as we1l.

One can further see why the technique Sargent chose (as also the technique chosen earlier by Sutch $|1968|$, Shiller $|1972|$ and Modigliani and Shiller) was as complicated as it was if one considers that with data only on $R_{t}^{(n)}$ and $R_{t}^{(1)}$ one cannot form the innovation in $R_{t}^{(n)}$ in terms of observed variables. With data in this paper and the expectations model $\tilde{H}_{t}^{(n)}-R_{t}^{(1)}$ is the innovation in the yield on an n-period bond, which is observable: $\tilde{H}_{t}^{(n)}-R_{t}^{(1)}=$ $\left(R_{t}^{(n)}-\gamma_{n} R_{t+1}^{(n-1)}\right) /\left(1-\gamma_{n}\right)-R_{t}^{(1)}$. Lacking data on $R_{t}^{(n-1)}$, however, one cannot observe this innovation. One can effectively observe $j_{j=0}^{n-1} r^{i}\left(H_{t+j}^{(n-j)}-R_{t+j}^{(1)}\right)$ because this equals, by our model, $((1-\gamma) /(1-\gamma))\left(R_{t}^{(n)}-j_{j} \sum_{0} \gamma r_{t+j}{ }^{j}(1)\right.$ but one cannot extract from a series of observations on this sum a series $H_{t}^{(n)}-R_{t}^{(1)}$.

\section{The Alternative llypothesis}

In framing alternative hypotheses about the term structure of interest rates, we must first bear in mind some basic facts about interest rates which atre consistent with the expectations model. We do not want our altermative hypothesis to deny these basic facts, otherwise our testing procedure would do no more than reflect facts that are already well known.

For large $n$ and short time intervals, it is well known that $H_{t}^{(n)}-R_{t}^{(1)}$ is approximately serially uncorrelated and not highly forecastable by other information, as our data here conf $1 \mathrm{rm}$, which is consistent with the implication 
of (1.) that $\mathrm{H}_{t}^{(n)}-\mathrm{R}_{t}^{(1)}$ is unforecastable. This fact is related to the fact that changes in long rates show low serial correlation. Secondly, it is well known that short rates have generally varied over a wider range than have long rates. In periods of tight credit short rates tend to be substantially higher than long rates. If short rates are stationary stochastic processes, then a high spread between short and long rates will tend to indicate, since a high spread tends to indicate a high short rate, that short rates will decline as the expectations model suggests. With our data there is indeed a negative correlation between $R_{t}^{(1)}-R_{t}^{(9)}$ and $\Delta R_{t+1}^{(1)}$. Third1y, the yield curve is generally a fairly smooth curve, which is consistent with smooth forecasts of the short rate. The smoothness of the yield curve coupled with the posftive serial correlation of short rates implies, for example, that $\mathrm{F}_{\mathrm{t}+\mathrm{i}}^{(1)} \mathrm{t}$ is positively correlated with $\mathrm{R}_{\mathrm{t}+1}^{(1)}$. Fourthly, in recent years the entire yield curve has shifted up. Both long, rates and short rates are higher in the 1970s than they were in the 1950 s wich suggests a positive correlation between holding yields and short rates or forward rates and spot rates.

None of the above facts, however, establish that the shape of the yield curve is a useful indicator of the path of future longer-term interest rates as predicted by our model. The first two facts noted above would remain true if we shifted the longest rate series $R_{t}^{(n)}$ and $R_{t}^{(n-1)}$ in time relative to the shortest rate series $R_{t}^{(1)}$ so as to throw them out of alignnent. The variable $H_{t}^{(n)}-K_{t}^{(1)}$ will remain approximately serially uncorrelated since $H_{t}^{(n)}$ is approximately serially uncorrelated and has a mucli larger variance than $R_{t}^{(1)}$

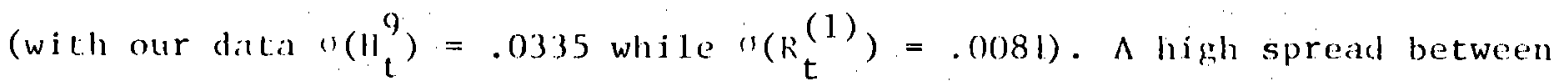
$R_{t}^{(1)}$ and $R_{t}^{(n)}$ may still tend to indicate that $R_{t}^{(1)}$ will fall since a high spread still tends to correspond to a high $\mathrm{R}_{t}^{(1)}$. Our third fact would remain true if we interpolated our misaligned long-term rate and one-period rate by any smooth yield curve each period, and $\mathrm{F}_{t+1, t}^{(1)}$ would still correlate highly with 
$R_{t+1}^{(L)}$. Only our fourth fact has anything to do at all with the alignment between long-term and one-period rate series. However, this fact is clearly consistent with the expectations model only as a characterization of very long-term or low frequency movements in interest rates.

All of the above basic facts are consistent with an alternative hypothesis that denies that the shape of the yield curve carries information about the future path of interest rates. Before defining it, recall what the null hypothesis says about the implications of the shape of the yield curve. If the yield curve (computed with demeaned data so that its average shape is flat) is upward sloping between 1 and $i$, i.e., if $\left(R_{t}^{(i)}-R_{t}^{(1)}\right)>0$, then the expected linearized one-period holding return $E_{t} \tilde{H}_{t}{ }^{(i)}$ must be less than the yield to maturity. Since the one period holding return equals the yield to maturity if $R_{t+1}^{(i-1)}=R_{t}^{(i)}$, an upward sloping yield curve must then require that the yield on the $i$-period bond increasing on average when $R_{t+1}^{(i)}$ is greater than $R_{t}^{(1)}$. Specifically, since $E_{t}\left(\tilde{H}_{t}^{(i)}-R_{t}^{(1)}\right)=0$, and since $R_{t}^{(i)}-R_{t}^{(1)}$ is known at time $t$, it follows from the definition of $\ddot{H}_{t}^{(i)}$ and the expectations operator that a regression of $R_{t+1}^{(i-1)}-R_{t}^{(i)}$ on $R_{t}^{(i)}-R_{t}^{(1)}$ should yield a coefficient of $\left(1-\gamma_{n}\right) / \gamma_{n}$ which is strictly greater than zero. Such a regression is identical, except for a linear dala transformation, to a regression of $k_{t+1}^{(i-1)}-k_{t}^{(i)}$ on $r_{t+1, t}^{(i-1)}-k_{t}^{(i)}$ except that now the coefficient must, by the mull hypothesis, be 1.00. This follows since, from the definition of $F_{t+1, t}^{(1-i)}, F_{t+1, t}^{(i-1)} t_{t}^{-} R_{t}^{(i)}=$ $\left(\left(1-r_{n}\right) / r_{n}\right)\left(R_{L}^{(i)}-R_{L}^{(1)}\right)$.

The alternative we shall consider (which was suggested by results with longer term bonds in Shiller $[1979]$ ) asserts that interest rates tend to move in the direction opposite to that indicated by the shape of the yield curve, i.e., that the coefficient in either of the above regressions is less than or equal to zero. The diagrams in figures 1 and 2 as described in the accompanying captions illustrate what is meant by the null as contrasted to this alternative. 
The long rate $R_{t}^{(i)}$ always lies between $R_{t}^{(1)}$ and $F_{t+1, t}^{(i-1)}$, by the definition of the linearized forward rate. The null hypotheses asserts that the distribution of: $R_{t+1}^{(i-1)}$ lies centered on the forward rate, so that $R_{t}^{(i)}$ tends to be between $R_{t}^{(1)}$ and $R_{t+1}^{(i-1)}$. The alternative hypothesis asserts that the distribution of $R_{t+1}^{(i-1)}$ is centered on the same side of $R_{t}^{(i)}$ as the short rate, i.e., $R_{t}^{(i)}$ does not tend to 1 ie between $\mathrm{R}_{t}^{(1)}$ and $\mathrm{K}_{t+1}^{(i-1)}$. The histograms shown give a visual impression of the truth of the expectations hypothesis. These diagrams are not ideal in that small values of the spread between long and short rates produce outliers in the histogram, and so observations for which the spread was small were eliminated (about $1 / 3$ of the observations). The figures suggest why regression tests of the null hypothesis are likely to have little power. The movements in actual interest rates are very large relative to the movements predicted, according to the expectations model, by the shape of the yield curve. The figures probably exaggerate the weakness of the test since they do not single out the occasional observation when the yield spread was large and therefore forecasted large movements in interest rates. The figures show that the validity of the expectations hypothesis may be sensitive to the choice of central tendency measure used to represent public expectations.

This alternative hypothesis represents an alternative so dramatically at variance with the expectations model of the term structure that it could not be reconciled with the model by such other considerations as tax effects or other coupon effects (as discussed in Shiller and Modigliani [1979]). 4 / If we consider the alternative only for one maturity, collapse the altermative to its upper bound, maintain the other coefficient restrictions of the null, and make an appropriate normality and homoscedasticity assumption,

4/ It is difficult to model tax effects directly because of the multiplicity of tax brackets, life cycle tax patterns, spectal tax provisions, changes in the law, relation of tax burden to holding pertod, etc. The simple model proposed by Shiller and Modigliani [1979] abstracts from nany of these problems. This model implies that when long rates are high relative to short rates, long rates are still expected to rise, but to rise somewhat less than in the simple expectations model due to the tax preference shown capital gains. 
TABLE II

REGRESSION RESULTS

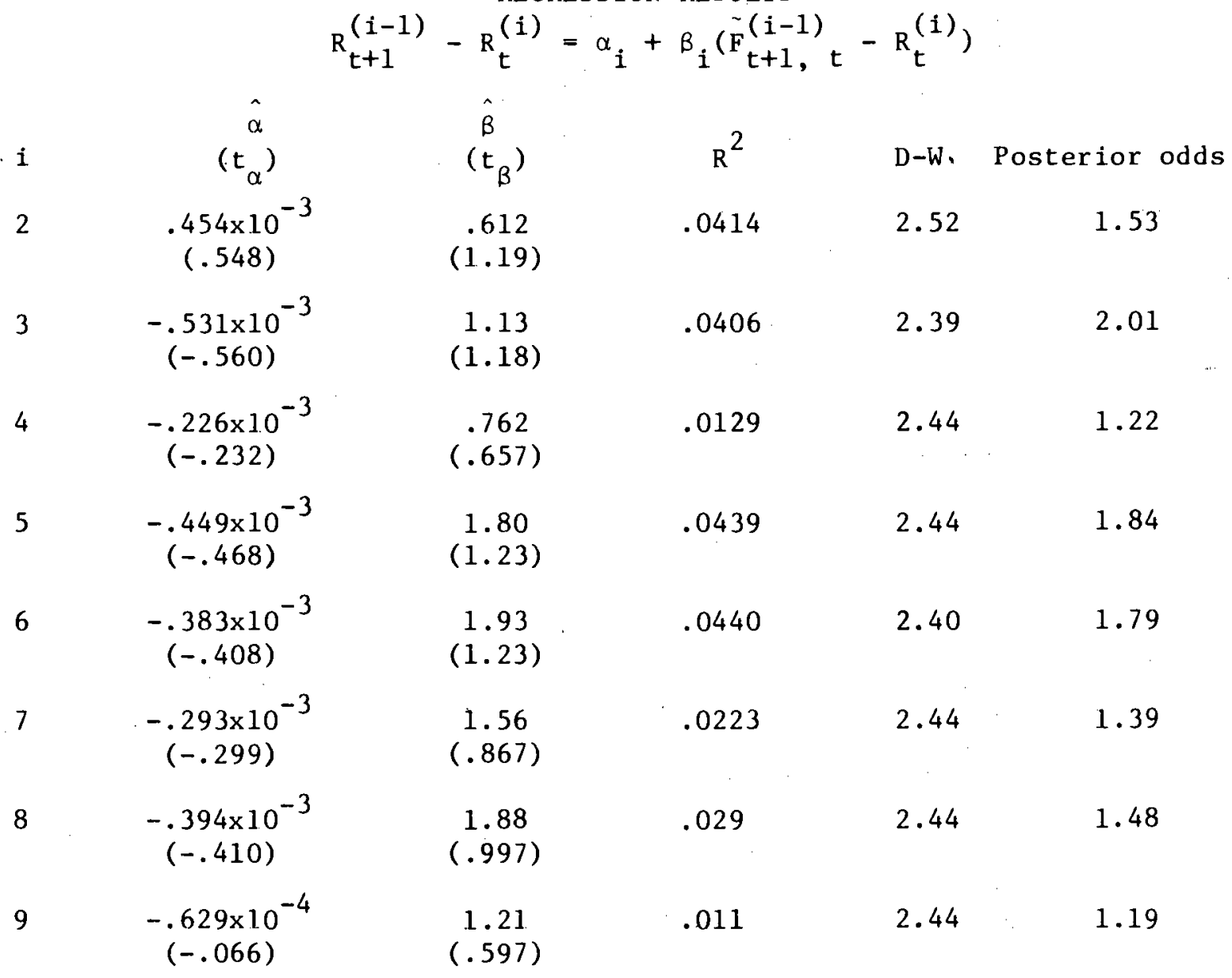

Source of data is Table III. The linearized (1-1) period forward rate applying to period $t+1, \tilde{F}_{t+1, t}^{(i-1)}$ is defined from Table IlI data as described in the text. The sample is 1955-II to 1972-II. Numbers in parentheses are $t$ statistics. 


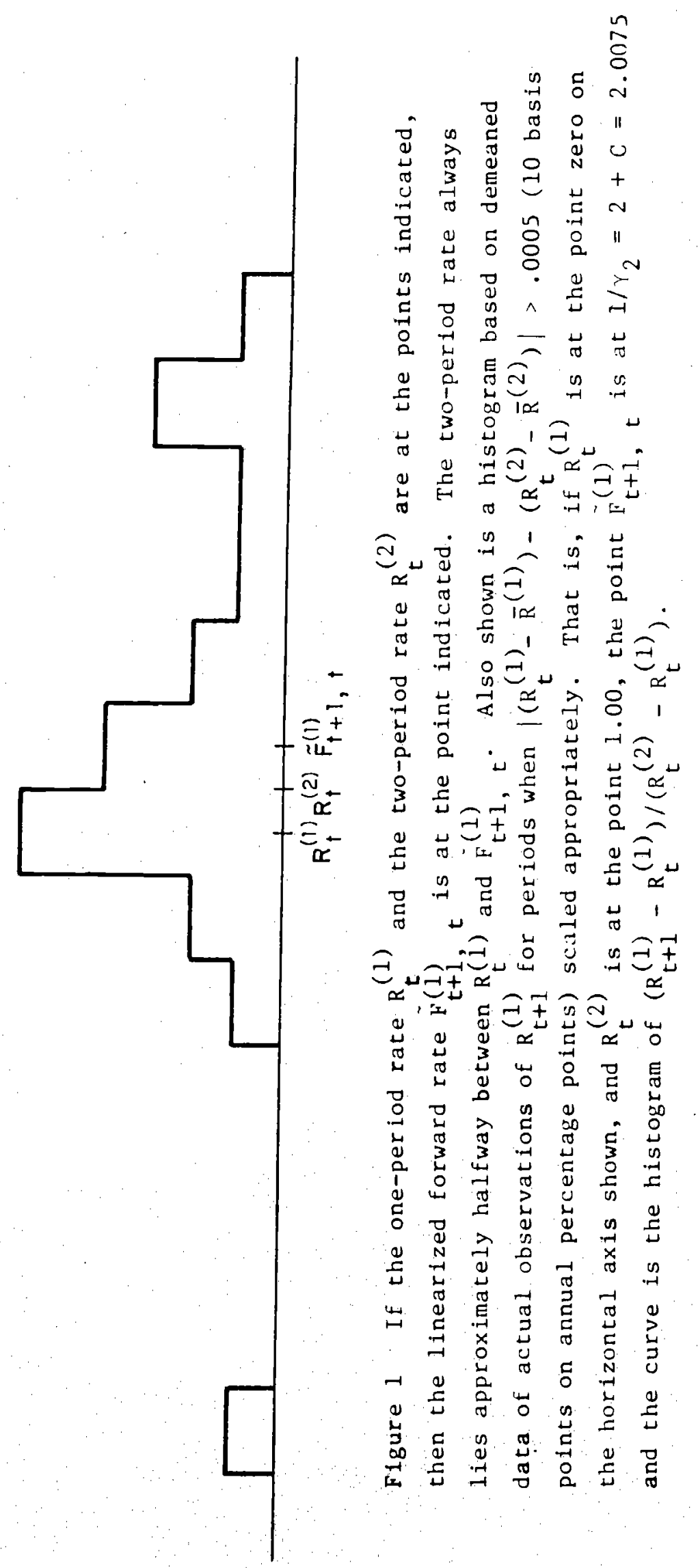




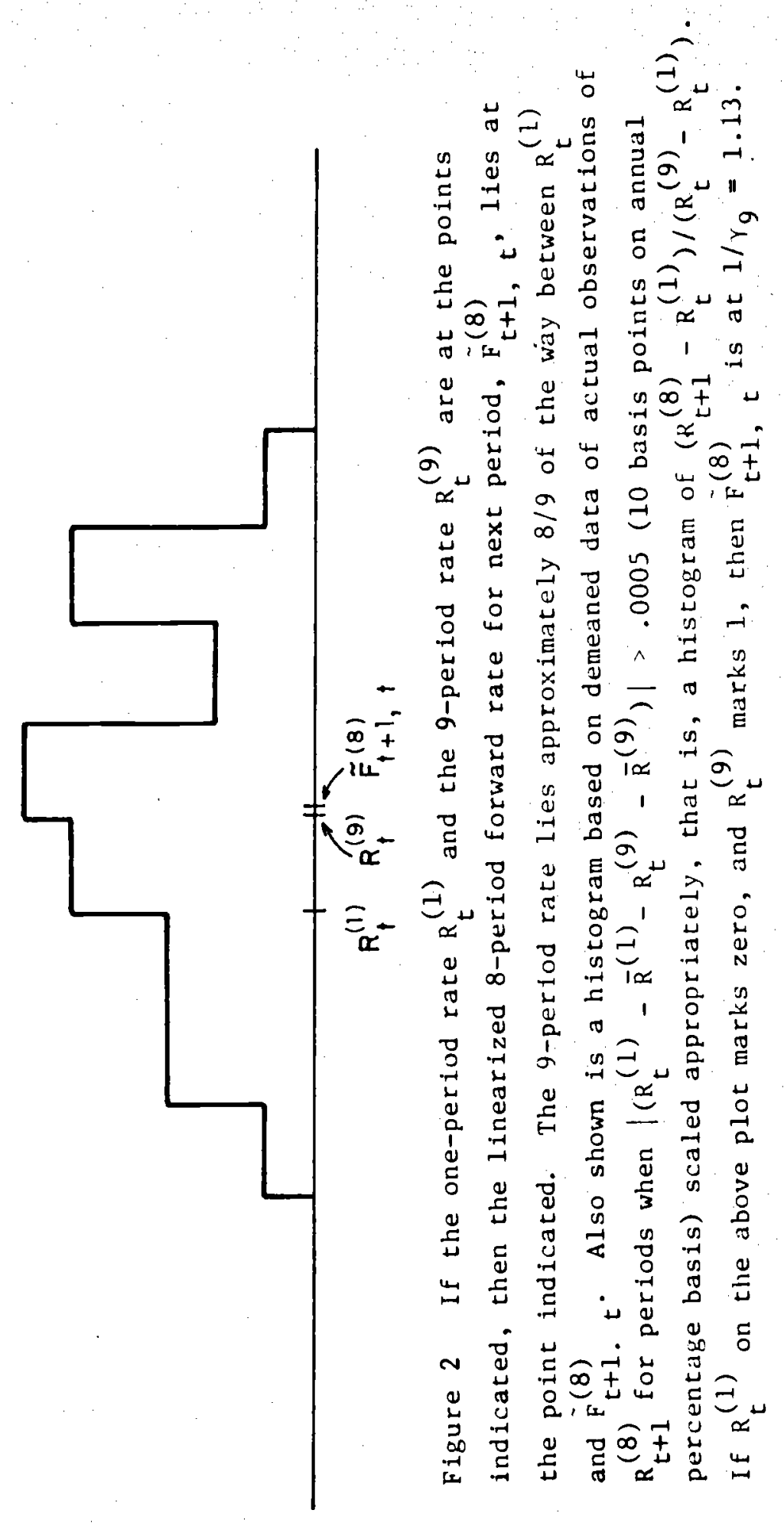


then the Neyman-Pearson lemma tells us that the best test is an ordinary regression t-test of a simple null versus simple alternative. One regresses the change in the long rate $R_{t+1}^{(i-1)}-R_{t}^{(i)}$ on a constant and the spread between the forward rate and the long rate $\tilde{F}_{t+1, t}^{(i-1)}-R_{t}^{(i)}$. The null hypothesis says that the coefficient of the spread is 1.00 . The alternative hypothesis described above states that the coefficient is less than or equal to zero, which we collapse now to a simple alternative that the coefficient equals zero. Had we chosen instead to give the alternative hypothesis a one-sided prior distribution below zero for the coefficient, along lines suggested by Zellner and Siow [1979], then the effect in our sample would be to increase the posterior odds, so that they would favor the null more strongly. One could increase the posterior odds ratio arbitrarily by giving more, weight in the alternative prior to very negative values of $\beta$.

The regression tests in Table II show some mild support for the expectations hypothesis but the support is very weak. $5 /$ The posterior odds ratio, based on a prior odds ratio of one, diffuse priors on the intercept and log uniform priors on the standard error of the regression ranges from 1.19 to 2.01. 6/

The results for the 8 different maturities shown in Table II are not independent. In fact, if we add to the null hypothesis that the forecasts of $R^{(1)}$ are based on a univariate ARIMA assumption, then the residuals should

5/ The regression tests shown in Table II are based on the arbitrary assumption of homoscedastic normal residuals, contrary to the distributional assumptions inplicit in figures 1 and 2 . The same regressions cannot be run using data from Salomon Brothers An Analytical Record... except for the case $i=2$. In this case, over our sample $\hat{\beta}=-.47$ and $\tau_{B}=-.39$. Thus, the result using the Salomon Brothers data is not significantly different from that reported in Table II.

6/ The posterior odds ratio is computed as $t\left(\left(1-\hat{\beta} / \hat{s_{\beta}}\right) / t\left((-\hat{B}) / \hat{S_{\hat{O}}}\right)\right.$ where $t(\cdot)$ gives the ordinate of t-distribution with $\mathrm{N}-\mathrm{K}=33$ degrees of freedom, $\hat{\beta}$ is the ordinary least squares estimate of $\hat{B}$, and $\hat{s}_{\hat{\beta}}$ is the usual estimated standard deviation of the estimate of $B$. 
be perfectly correlated. If we wished to compute posterior odds ratios that all coefficients are 1 versus the alternative that all are zero we would need to consider the correlation of residuals across equations.

A natural assumption to make is the uninformative prior on the $(i-1) \times(i-1)$ covariance matrix of residuals $\Sigma$, of the form $f\left(\Sigma^{-1}\right)^{\propto}\left|\Sigma^{-1}\right|^{-\frac{1}{2}}$ which results from a Wishar prior on $\Sigma$ as the degrees of freedom in the prior go to zero. Zellner [1971] shows the marginal posterior for our model which, however, does not reduce to a generalized multivariate student $t$ distribution.

\section{Conclusion and Summary}

We have seen how the complicated nonlinear restrictions implied by expectations models on the cross autocovariance functions of interest rates shown by Sutch [1968], Shiller [1972], Modigliani and Shiller [1973] and Sargent [1979] are the result of omitted variables in their analysis. With the complete vector of interest rates used here, the restrictions are of the simple linear variety which can be tested by simple regression tests rather than the asymptotic $x^{2}$ likelihood ratio test of the nonlinear constraints used by Sargent [1979]. Precisely which regressions to run depends on the alternative hypothesis of interest. An alternative hypothesis was proposed which represents the notion that the shape of the yield curve does not give the right signals as to the likely future path of interest rates. Although the data favored this alternative hypothesis with the long term (over 20 year) bonds in Shiller [1.979], the data on short to intermediate tern bonds used here, Table II, favor the expectations hypothesis. The results thus suggest that there may be an element of truth to the expectations hypothesis for short or intermediate term interest rates but posterior odds ratios show that the evidence is very weak. Before general conclusions are reached about short to intermediate term 
interest rates and the rational expectations model, these procedures ought to be applied to other data sets as well. In view of these results, it is perhaps not surprising that Sargent's tests, which used similar data and sample period, accepted the model. His procedure is, however, slightly different from that used here and was not directed at testing against the alternative hypothesis considered here. 
TABLE III

YIELDS TO MATURITY (R) ON $1.5 \%$ U.S. TREASURY NOTES, END OF MARCH \& SEPTEMBER*

1955-II to 1973-I

\begin{tabular}{|c|c|c|c|}
\hline & $\begin{array}{c}i=1 \\
6 \text { months }\end{array}$ & 12 months & 13 months \\
\hline $\begin{array}{l}1955-I T \\
1956-1\end{array}$ & $\begin{array}{l}0.91410251 \\
0.9196583 \\
0.9125629\end{array}$ & $\begin{array}{l}9.0190371 \\
0.0125916\end{array}$ & $\begin{array}{l}9119803 \\
0.9134915\end{array}$ \\
\hline $1957-I$ & $\begin{array}{l}9.9125629 \\
1.9135364 \\
9.117908 ?\end{array}$ & $\begin{array}{l}0.0145252 \\
0.0145253 \\
0.0171163\end{array}$ & $\begin{array}{l}0.0163125 \\
0.915666 \pi \\
0.019390 ?\end{array}$ \\
\hline 1958-I & $\begin{array}{l}x .9071847 \\
.913 B 364\end{array}$ & $\begin{array}{l}9.997599 a \\
9.9139894\end{array}$ & $\begin{array}{l}9.9191974 \\
0.0152 ? 96\end{array}$ \\
\hline $1959-I$ & 0.9144746 & 0.0151711 & 0.9159797 \\
\hline $\begin{array}{cc}1960-\mathrm{I} \\
1961-\mathrm{I}\end{array}$ & 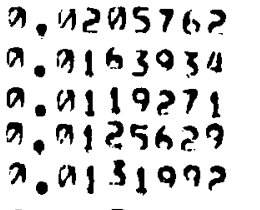 & $\begin{array}{l}9.0>39290 \\
0.0151711 \\
0.0125946 \\
0.9125946 \\
0.0129156\end{array}$ & $\begin{array}{l}9.9229765 \\
9.9171191 \\
0.9130587 \\
0.0141419 \\
0.9147930\end{array}$ \\
\hline $1962-\mathrm{I}$ & $\begin{array}{l}a .912 B 399 \\
a .1138364\end{array}$ & $\begin{array}{l}0.0125946 \\
0.0125916\end{array}$ & $\begin{array}{l}9135997 \\
9.9127347\end{array}$ \\
\hline $\begin{array}{l}1963-\mathrm{I} \\
1964-\mathrm{I}\end{array}$ & $\begin{array}{l}\pi .9128999 \\
0147959 \\
9163934\end{array}$ & $\begin{array}{l}0.0125946 \\
0.0151711 \\
0.0167914\end{array}$ & $\begin{array}{l}9.9132759 \\
9.1154977 \\
9.9171993\end{array}$ \\
\hline $1.965-1$ & $\begin{array}{l}7.9157531 \\
9.1163934\end{array}$ & $\begin{array}{l}0.0154945 \\
0.016953 A\end{array}$ & $\begin{array}{l}9.9167503 \\
0.9171993 \\
0.9183903\end{array}$ \\
\hline $1966-\mathrm{I}$ & $\begin{array}{l}. .1193194 \\
7.9196978 \\
0.0234923\end{array}$ & $\begin{array}{l}9.0189932 \\
4.9219497 \\
9.944780\end{array}$ & $\begin{array}{l}0.993619 \\
9529 a 79\end{array}$ \\
\hline $1967-I$ & 9.0183196 & a. & $9.9185>19$ \\
\hline & 9.9228427 & V. H?2ח & $a, a 232913$ \\
\hline $1968-I$ & $\begin{array}{l}9.9528427 \\
9.95349 ? 2\end{array}$ & $\begin{array}{l}0.0340139 \\
0.0729280\end{array}$ & $\begin{array}{l}a .954, a 5 h \\
0.0235413\end{array}$ \\
\hline 1969-I & 0.9274059 & 0.19283546 & 9.92A1989 \\
\hline $1970-\mathrm{I}$ & $\begin{array}{l}a .0359298 \\
a .91140114\end{array}$ & $\begin{array}{l}0.0372043 \\
0.6379943\end{array}$ & $\begin{array}{l}0.03561131 \\
0.14370632\end{array}$ \\
\hline $1.971-\mathrm{I}$ & $\begin{array}{l}9.0373230 \\
0.9176769 \\
9.0254454\end{array}$ & $\begin{array}{l}0.0344573 \\
9.01811195 \\
0.0 ? 79131\end{array}$ & $\begin{array}{l}9.9351715 \\
a .9197420 \\
a .0286579\end{array}$ \\
\hline & $\begin{array}{l}\text { a. } 9254454 \\
\Rightarrow .9289611\end{array}$ & 9.0587506 & $\begin{array}{l}\text { a. } 9258356 \\
9.929777\end{array}$ \\
\hline $1973-I$ & $\pi .0346590$ & 0.0737736 & a. 1323590 \\
\hline
\end{tabular}

*Exact yields to maturity computed using midpoint of bid-asked price as reported on Rodney White Center Governmental Bonds Tape. Multiply by 200 to convert to annual percent. 
TABLE III - (continued)

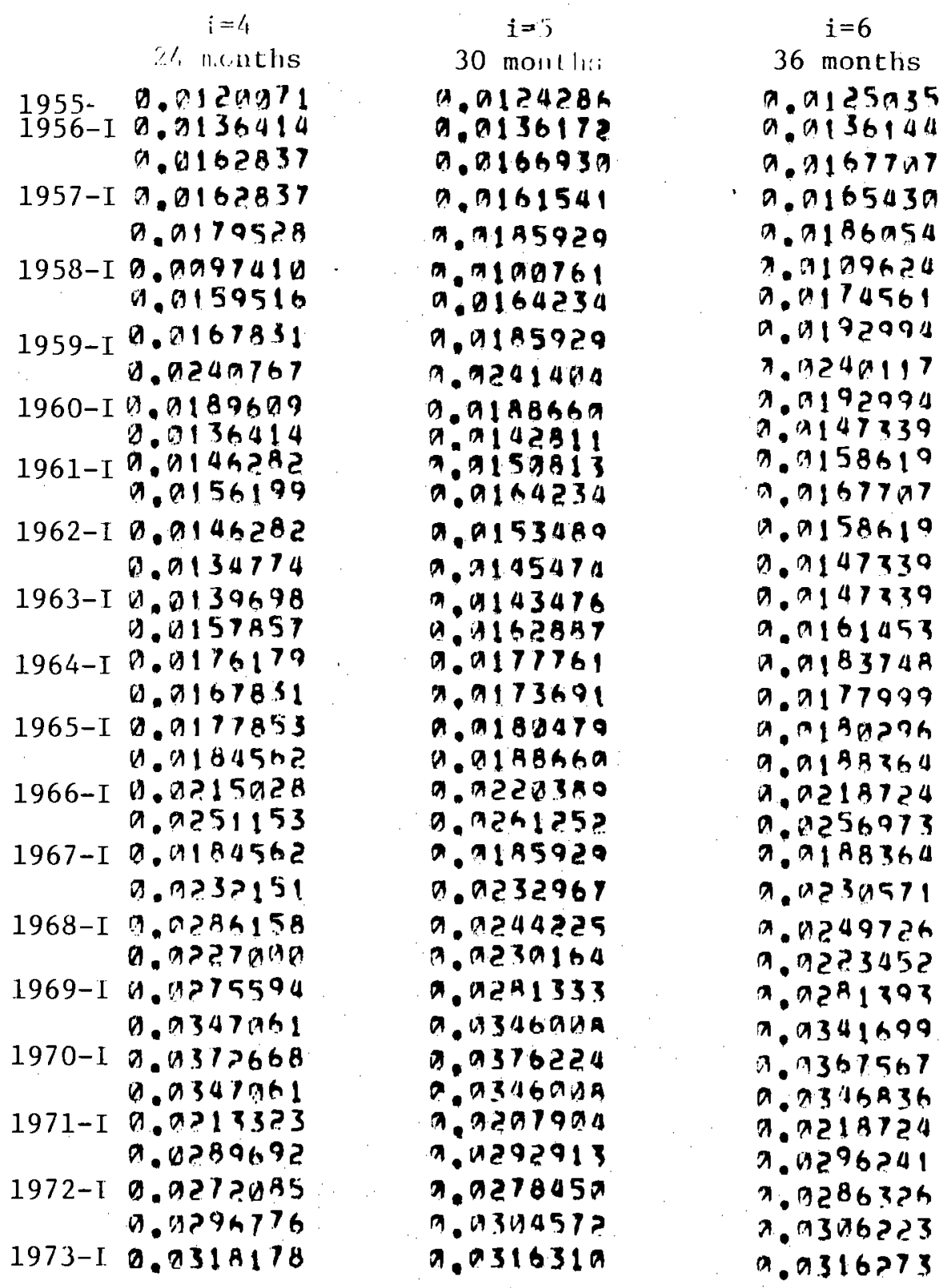


TABLE III - (continued)

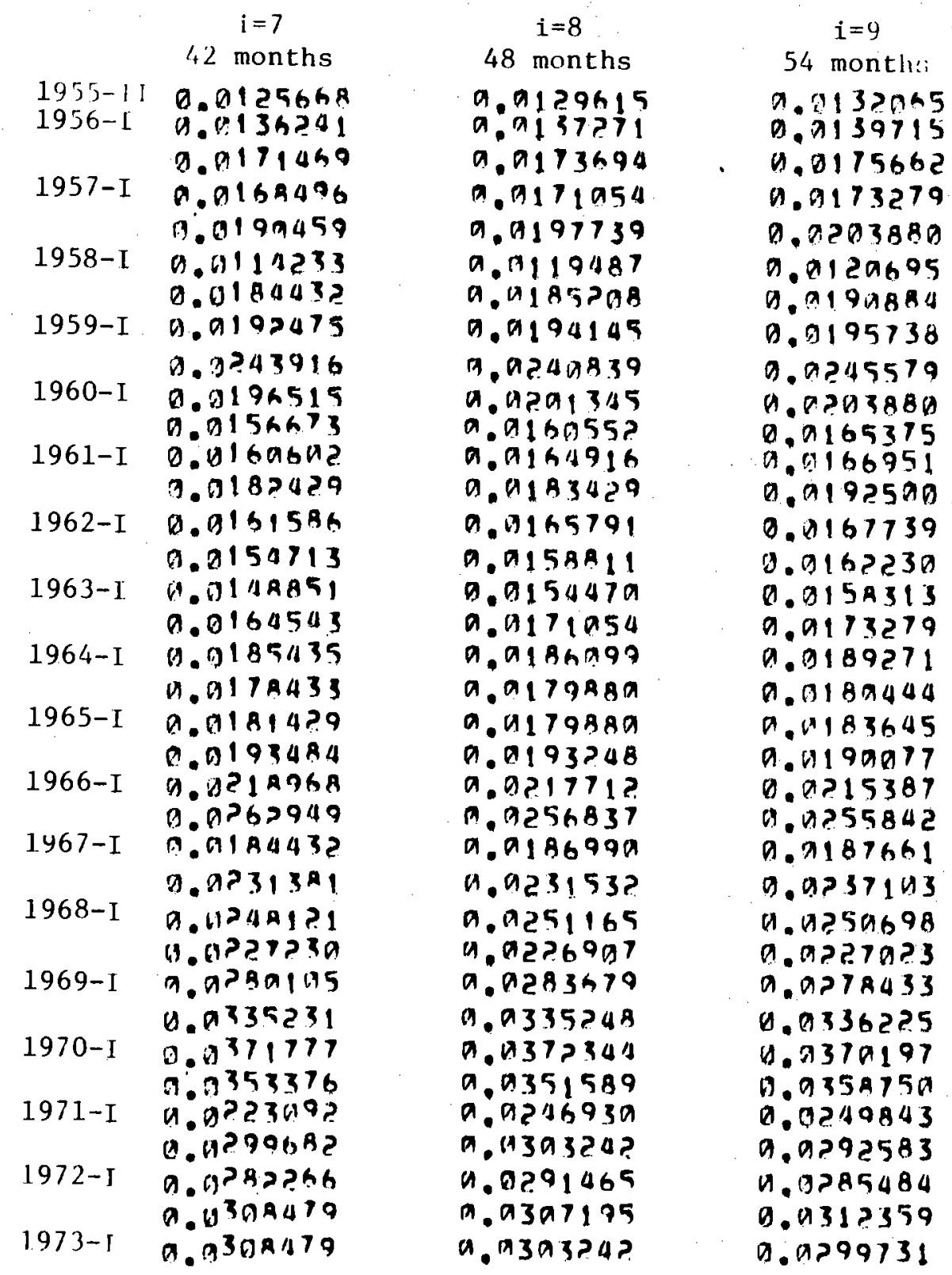




\section{REFERENCES}

Bildersee, John S., "Some N€w Bond Indexes," Journal of Business, 48: 506-25, 1975.

Cox, John C., Ingerso11, Jonathan E., Jr., and Stephen A. Ross, "A Theory of the Term structure of Interest Rates and the Valuation of IntcrestDependent Claims," mimeographed, Stanford University, 1977.

LeRoy, Stophen and Richard Porter, "The Present Value Relation: Tests Based on Implied Variance Bounds," Econometrica, March 1981.

Melino, Angelo, Testing Ratinnal Fxnectations Mndels of the Term Structure, unpub1ished Ph,D. Dissertation, Harvard University, 1981.

Modigliani, Franco and Robert Shiller, "Inf]ation, Rational Fxpertations, and the Term Structure of Interest Rates," Economica, 40: 12-43, February 1973.

Richards, Scott, "An Arbitrage Model of the Term Structure of Interest Rates," Journa1 of Financia1 Economics, 6: 33-57, March 1978.

Salomon Brothers, An Analytical Record of Yields and Yield Spreads, Salomon Brothers, Inc., Sixty Wall Street, New York, NY.

Sargent, Thomas J., "A Note on Maximum Likelihood Estimation of the Rational Expectations Model of the Term Structure", Journal of Monetary Economics, 5: 133-43, January 1979.

Shiller, Robert J., "Do Stock Prices Move Too Much to be Justified by Subsequent Changes in Dividends?", forthcoming, American Economic Review, 1980a. "Rational Expectations and the Structure of Interest Rates," PhD) dissortation, Ml't, 1972. , "The Use of Volatility Measures in Assessing Market Efficiency," mimeographed, National Bureau of Economic Research, $1980 \mathrm{~b}$. , "The Volatility of Long-Term Interest Rates and Expectations Models

of the Term Structure," Journal of Political Economy, 87:1190-1219, December 1979 . 
............. and Franco Modigliani, "Coupon and Tax Effects on New and Seasoned Bond Yields and the Measurement of the Cost of Debt Capital," Journal of Einancial Economics, vol. 7, no. 3, December 1979.

Singleton, Kenneth, "Expectations Models of the Term Structure and Implied Variance Bounds," Journal of Political Economy, 1980.

Sutch, Richard, "Expectations, Risk and the Term Structure of Interest Rates," unpublished PhD dissertation, MIT, 1968.

Zellner, Arnold, "Posterior Odds Ratios for Regression Hypotheses," mimeographed, University of Chicago, 1979.

, " $\Lambda \mathrm{n}$ Introduction to Bayesian Inference in Econometrics", Wiley, 1979. and Aloysius Siow, "On Posterior Odds Ratios for Sharp Null Hypotheses and One-Sided Alternatives," mimcugraphed, University of Chicago, 1979. 